\title{
DER KRAKAUER WOJEWODE TEODOR GRYFITA (GEST. NACH 1237) UND DIE HL. KUNIGUNDE VON POLEN AUS DER ÁRPÁDEN-DYNASTIE (1234-1292) ALS STIFTER DER ÄLTESTEN KLÖSTER IM PODHALE
}

Anfang des I3. Jahrhunderts war das Podhale ein Gebiet, auf dem sich umfangreiche, dem Adel und Rittertum sowie der Kirche gehörende Landgüter entwickelten. Die bisherige Fachliteratur ist sich darüber einig, dass es dort Ende des II. Jahrhundert ein Netz von Burgwall-Kirchen gab; den Ursprung der eigentlichen Dorfpfarreien erkennt sie wiederum in den seit dem Anfang des I2. Jahrhunderts entstehenden Privatkirchen, die mit den großen feudalen, entweder dem Fürsten oder dem Rittertum gehörenden Gütern verbunden waren ${ }^{\mathrm{I}}$. Im I3. Jahrhundert wurde die Entwicklung des Pfarrei-Netzes im Podhale vom Auftreten der ersten Klosterstiftungen begleitet, deren Eigentumsabhängigkeit ziemlich schnell von der fürstlichen auf die kirchliche überging. Der Prozess von Klosterstiftungen hatte seinen Ursprung sowohl in der fortschreitenden Christianisierung Polens als auch im Fortgang des Besiedlungsprozess ${ }^{2}$.

Beweggründe für mittelalterliche Klosterstiftungen waren vor allem religiöser Natur; die Stiftungen konnten aber auch durch die mit dem Besiedlungsprozess verbundenen Faktoren veranlasst werden. Im Falle der Zisterzienser-Stiftung von Ludźmierz und Szczyrzyc waren beide Motive von Bedeutung. Stifter des Zisterzienserklosters in Ludźmierz-Szczyrzyc war der Krakauer Wojewode Teodor (Czader, Cedro) Gryfita - Besitzer eines beträchtlichen Teiles des Neumarkt-Landes. Die Familie Gryfita zählte zu den einflussreichsten kleinpolnischen Geschlechtern und wurde durch ihre zahlreichen großzügigen Stiftungen berühmt: sie stiftete u. a. das Zisterzienserkloster in Jędrzejów sowie das Kloster des Ordens der Ritter vom Heiligen Grab zu Jerusalem in Miechów und das Benediktinerkloster in Staniątki. Sie

\footnotetext{
* Prof. zw. dr hab. Jolanta M. Marszalska - profesor zwyczajny w Instytucie Nauk Historycznych Wydziału Nauk Historycznych i Społecznych Uniwersytetu Kardynała Stefana Wyszyńskiego w Warszawie. Prowadzi badania nad staropolska kulturą piśmiennictwa, monastycyzmem, księgozbiorami klasztornymi: benedyktynów, cystersów, bernardynów i karmelitów bosych, historycznymi księgozbiorami diecezji tarnowskiej i płockiej oraz księgozbiorami i dziejami rodów magnackich.

1 A. Rutkowska-Płachcińska, Sądeczyzna w XIII $i$ XIV w. Przemiany gospodarcze i społeczne, Wrocław - Warszawa - Kraków 1961, S. 18.

2 J. Zawadzka, Proces fundowania opactw cysterskich w XII i XIII wieku, „Roczniki Humanistyczne”, 7/1960, H. 2, S.121-150; S. Zakrzewski, Najdawniejsze dzieje klasztoru cystersów w Szczyrzycu (1238-1382). Przyczynek do dziejów osadnictwa na Podhalu, Kraków 1901, S. 22; J. Rafacz, Dzieje i ustrój Podhala nowotarskiego za czasów dawnej Rzeczypospolitej Polskiej, Warszawa 1935, S. 23-25.
} 
stammte vermutlich aus Brzeźnica bei Bochnia in Kleinpolen ${ }^{3}$. Als Stammvater der Familie gilt Klemens I. Gryfita, der zusammen mit seinem Bruder - dem Gnesener Erzbischof Janik - das Zisterzienserkloster in Brzeźnica-Jędrzejów stiftete ${ }^{4}$. Neben einer Tochter namens Anna hatte Klemens I. noch drei Söhne: Klemens, Andrzej und Jan. Es ist anzunehmen, dass Klemens - später der Zweite genannt - sein erstgeborener Sohn und daher Erbe des väterlichen Erbgutes Brzeźnica bei Bochnia war5. Andrzej wurde Krakauer Kanoniker, während Jan (miles) der Vater des Krakauer Woiwoden Marek sowie des schon genannten Krakauer Woiwoden Teodor war, des Stifters des Klosters von Szczyrzyc ${ }^{6}$. Nicht ohne Bedeutung war wohl die Tatsache, dass Teodor Gryfita keine direkten Erben hinterließ. In einer von Teodor für das Zisterzienserkloster in Jędrzejów am 4. Mai I236 ausgestellten Urkunde wird zwar an einer einzigen Stelle sein Sohn Piotr (Petrus Theodori filius) als Zeuge erwähnt ${ }^{7}$, doch überlebte er vermutlich seinen Vater nicht - sonst wäre er zu einem Patron des von Teodor gestifteten Klosters geworden. Dementsprechend ist nicht auszuschließen, dass Teodor mit seiner Entscheidung für eine Klosterstiftung seine Güter schützen sowie sich Gebete für sich selbst und das ganze Geschlecht sichern wollte. Doch warum wählte er gerade den Zisterzienserorden? Mit der Klosterstiftung beabsichtigte er vermutlich, Grundlagen für die Siedlungs- und Wirtschaftstätigkeit zu schaffen, und der Zisterzienserorden war im damaligen Europa bereits durch seine Erfolge bei der Verbesserung der landwirtschaftlichen Verhältnisse bekannt, was somit eine erfolgreiche Bewirtschaftung der noch wilden Gebiete des Neumarkt-Landes erwarten lie $\beta^{8}$. Darüber hinaus wurde der Krakauer Wojewode I234 von Heinrich I. dem Bärtigen - Herzog von Schlesien und des Krakauer Landes - mit der Aufgabe beauftragt, das Podhale zu kolonisieren, wodurch der Stiftungsprozess in Gang gesetzt wurde.

Das Zisterzienserkloster in Ludźmierz-Szczyrzyc, dessen Mönche auf Veranlassung des Krakauer Wojewoden Teodor Gryfita gegen I234/I235 von der Stiftung der Gryfita-Familie in Jędrzejów geholt wurden, war die älteste Stiftung im Podhale. Zum ersten Male wurde das Kloster von Szczyrzyc in einer Urkunde von I234 erwähnt ${ }^{9}$. (Dasselbe Datum wird von Jan Długosz angeführt.)

„Theodorum appellare, Cedronem, et omnes eiusdem nominis appellationem sortitos vocavit cultum divinum amplificaturus, et sibi viam structurus in coelum, in villa sua haereditaria Ludzimirz prope Nowitharg oppidum, sub montibus sarmaticis seu polonicis sita, monasterium ordinis Cisterciensis sub titulo et honore Sanctae Mariae, anno Domini 1234, sub pontificio Viszeslai Cracoviensis episcopi, et sub principatu Bole-

\footnotetext{
P. Sczaniecki, Gryfici z linii brzeźnickiej i benedyktyni, „Studia Historyczne”, 30/1987, H. 1, S. 5; 15-16.

4 J. Dobosz, L. Wietesko, Jędrzejów, In: Monasticon Cisterciense Poloniae (weiter: MCP) Bd. 2, hrsg. A.M. Wyrwa, J. Strzelczyk, K. Kaczmarek, Poznań 1999, S. 91.

5 Ebd.

6 Ebd., S. 4, Fußnote Nr. 103.

7 J.M. Marszalska, Opactwo cystersów w Szczyrzycu od XIII do końca XX wieku. Dzieje, gospodarka, kultura, Kraków 2011, S. 38.

8 Ebd., S. 43-44 (dort Verweise auf umfangreiche Literatur)

9 Kodeks Dyplomatyczny Małopolski (weiter: KDM), Bd. 1, hrsg. F. Piekosiński, Kraków 1876, Nr. XXVI, S. 3132.
} 
slai Pudici Cracoviensis et Sandomieriensis ducis, regni Poloniae monarchae, et de eorum speciali consensu fundat $[\ldots]^{“ 10}$.

Kraft der I234 in Danków ausgestellten Urkunde genehmigte der Herzog von Schlesien und des Krakauer Landes Heinrich I. der Bärtige dem Krakauer Wojewoden Teodor Gryfita die nach deutschem Recht vollzogene Gründung eines Dorfes am Dunajec sowie von sieben weiteren, an kleineren Flüsschen gelegenen Dörfern ${ }^{\mathrm{II}}$. Im selben Jahre erteilte der Krakauer Bischof Wisław von Kościelec (gest. I242) dem Wojewoden seine Zustimmung zur Stiftung eines Klosters und zur Errichtung einer Kirche in Ludźmierz ${ }^{12}$. Wisław gewährte dem Kloster mit Zustimmung des Kapitels auch den Garbe-Zehnten von allen Dörfern, die in den Klostergütern gegründet werden sollten ${ }^{13}$. Für das von ihm gestiftete Kloster erwarb der Wojewode die Dörfer Godusza und Gruszowiec, was in einer am II. Mai I235 ausgestellten Urkunde von zwei Krakauer Kanonikern - dem Domherr Nikolaus und einem Geistlichen namens Herman - bestätigt wurde: ,proprio claustro quod vocatur Ludzimierz iure hereditario possidendam [...] "“4 . Daneben verlieh der Krakauer Wojewode dem Zisterzienserkloster in Jędrzejów zwecks einer neuen Stiftung ein Areal, das Ludźmierz heißt, mit dazugehörenden Gebieten und einer Salzgrube sowie die Dörfer: Brunaczów, Mogilany, Osieczany, Droginia und Niedzieliska, die eine Meile von Szczyrzyc enfernten Wiesen sowie Szczyrzyc selbst, Góra Św. Jana und eine Salzgrube in Bochnia ${ }^{15}$.

Gegen I234/I235 kam vom Mutterkloster in Jędrzejów der erste quellenkundlich bezeugte Abt namens Tecelin mit zwölf Ordensbrüdern nach Ludźmierz ${ }^{16}$. Sein Name Tecelin deutet auf eine ausländische Herkunft hin. Unter Berücksichtigung der Tatsache, dass er vom Kloster in Jędrzejów kam, das eine Filiation des Klosters Morimond war, und dass dessen Belegschaft wiederum fast ein Jahrhundert lang nach der gegen II40 erfolgten Stiftung aus Mönchen fremder Herkunft bestand, ist anzunehmen, dass der Abt aus Frankreich stammte ${ }^{17}$. Die erhalten gebliebenen Urkunden bestätigen, dass Tecelin schon I238 als Abt von Ludźmierz einen Rechtstreit gegen den Comes Zdzisław Gryfita um das Schirmherrschaftsrecht über die

10 J. Długosz, Liber Beneficiorum Dioecesis Cracoviensis, Bd. 3, Cracoviae 1864, S. 436.

11 KDM, Bd. 1, Nr. XV, S. 21-22; W. Kolor, Cysterski klasztor w Szczyrzycu, 1881, S. 1, (Typoskript), ohne Signatur; B. Biros, Dzieje opactwa oo. Cystersów w Szczyrzycu na tle życia i zasług opatów tegoż klasztoru, Szczyrzyc 1950, S. 5, (Typoskript), ohne Signatur.

12 KDM, Bd. 1, Nr. XIV, S. 21; W. Kolor, Cysterski klasztor w Szczyrzycu..., S. 1; J.M. Marszalska, Opactwo cystersów w Szczyrzycu od XIII do końca XX wieku, Kraków 2011, s. 39.

13 Słownik historyczno-geograficzny województwa krakowskiego w Średniowieczu (weiter: SHGWK), hrsg.. F. Sikora, T. 3, H. 3, Kraków 2000, S. 74.

14 J.M. Marszalska, Opactwo cystersów w Szczyrzycu od XIII do końca XX wieku..., Kraków 2011, S. 39.

15 SHGWK, bearb. Z. Leszczyńska-Skrętowa, F. Sikora, T. 1, H. 1, Wrocław-Warszawa-Kraków-Gdańsk 1980, S. 156; SHGWK, hrsg. F. Sikora, T. 3, H. 3, S. 745.

16 W. Kolor, Cysterski klasztor w Szczyrzycu..., S. 1; B. Biros, Dzieje opactwa, (Typoskript), S. 1; T. Magiera, Series Antistitum Monasterii Szczyrzyc [...] Series Abbatum Szczyrzycensium. In: Xenia Bernardina, Bd. 3, Wien 1891, S. 317; Servitus Sancta coram Deo, et omnibus Sanctis eius per voturum missionem secundum Regulam S.P. Benedicti Constitutiones Ordinis Cisterciensis [...] compilata [...] descriptus 1751, Bd. 3, ohne Signatur..

17 Thislinus seu Thecilinus unicus abbas monasterii Ludzimiriensis, qui ex verisimiliori authorum opinione ex monasterio Andreoviensis adductus 1234 in Ludzimierz [...]. Vgl. Servitus Sancta, S. 3. Auf französische Herkunft von Tecelin weist auch B. Biros hin. Vgl. B. Biros, S. 1; L. Janauschek, Originum Cisterciensium, Bd. 1, Vindobonae 1877, S. 243. 
Kirche in Szczyrzyc führte ${ }^{18}$. Schiedsmänner in diesem Streit waren die damals berühmten Kanonisten Salomon - profesor iuris, Kanoniker des Krakauer Kapitels - sowie Ugier, genannt Buzakarinus - ein gebürtiger Italiener, der ebenso profesor iuris war ${ }^{19}$. Die als Schiedsrichter (pacis compositores) berufenen Geistlichen sprachen das Schirmherrschaftsrecht zusammen mit dem dazugehörenden Zehnten dem Zisterzienserkloster zu. Darüber hinaus bestimmten sie, dass Zdzisław dem Abt die Schlüssel und die Kirchenausstattung übergeben sollte und das Kloster mit der Schirmherrschaftsangelegenheit nicht weiter belästigen dürfte. Dem Gemeinwohl zuliebe wurde das Kloster im Gegenzug verpflichtet, den Comes Zdzisław und seine Nachfahren als Erben des Klosters anzuerkennen und ihnen dementsprechend die gebührende Ehre zu bezeugen ${ }^{20}$. Die entsprechende Urkunde wurde im Mutterkloster in Jędrzejów verfasst. Szczyrzyc selbst gehörte, was in den Urkunden von I244 und I254 bestätigt wurde, Teodor Gryfita, der das Dorf von seinem Neffen Sulisław, einem Krakauer Kanoniker, gekauft hatte ${ }^{21}$.

Die im Vergleich zu Ludźmierz, das zum Podhale gehört, günstigere Lage von Szczyrzyc war für die Entscheidung, das Kloster zu verlegen, ausschlaggebend. Ludźmierz lag am Schwarzen Dunajez, der häufig die nahe gelegenen Gebiete überflutete. Die Stradomka, an der Szczyrzyc lag, war dagegen ein kleiner, im Verhältnis zu Dunajez viel weniger aufgestauter Fluss; darüber hinaus begünstigten die sanften Berghänge der Beskiden den Acker- und Gartenbau. In dieser Gegend war es auch leichter, Verkehrswege abzustecken. Schließlich war das Gebiet um Szczyrzyc sicherer, insbesondere da sich in der Nähe des jetzigen Klosters seit den Zeiten der Lausitzer Siedlungstätigkeit ein Burgwall befand ${ }^{22}$. Eine unmittelbare Ursache der Klosterverlagerung war allem Anschein nach der Tataren-Überfall I24I und die daraus resultierenden Verwüstungen. Das Kloster wurde wahrscheinlich zwischen I24I und 243 verlegt. Zum ersten Male wurde die Stiftung von Teodor Gryfita als monasterio de Cyrich in einer Urkunde von Herzog Bolesław V. dem Schamhaften (I243-I279) aus dem Jahre I243 erwähnt, in der der Verkauf des Dorfes Mogilany bestätigt wurde ${ }^{23}$.

Nach dem Tod von Teodor Gryfita (nach I237) wurden seine Neffen Klemens und Marek zu Hauptpatronen des Klosters. In der Urkunde vom Jahre I254 bestätigten sie das Eigentumsrecht des Klosters über die weit ausgedehnten Untergebirgsgebiete und wandten ihm daneben: ,[...] duas villas, videlicet Drogynam cum molendino et thaberna, et brenczowicz cum una sorte Popowicz [...]“ zu$^{24}$. Am I4. Mai I252 bestätigte der Krakauer Herzog Bolesław V. der

\footnotetext{
18 Es ist zu bemerken, daß bei dieser Gelegenheit zum ersten Male „ecclesia de Cjirce“ erwähnt wurde. Siehe: KDM, Bd 1, hrsg. F. Piekosiński, Kraków 1876, Nr. XXIII, S. 28-29.

19 M. Rechowicz, Początki i rozwój kultury scholastycznej (do końca XIV w.), In: Dzieje teologii katolickiej w Polsce, Bd. 1, Średniowiecze, hrsg. M. Rechowicz, Lublin 1974, S. 49, 366.

20 SHGWK, bearb. J. Laberschek, Z. Leszczyńska-Skrętowa, F. Sikora, T. 1, H. 4, Wrocław-Warszawa-Kraków 1986, S. 831; SHGWK, hrsg. F. Sikora, T. 3, H. 3, S. 745.

${ }^{21} K D M$ Bd. 1, nr XXVII, S. 32-33; Nr. XL, S. 44-45; L. Janauschek, Originum Cisterciensium, Bd. 1, S. 243; E. Łużyniecka, J. M. Marszalska, Szczyrzyc, Dzieje budowy opactwa cysterskiego, Wrocław 2005, S. 89; B. Kwiatkowska-Kopka, Ludźmierz-Szczyrzyc. In: MCP, Bd. 2, hrsg. A.M. Wyrwa, J. Strzelczyk, K. Kaczmarek, Poznań 1999, S. 221. Der verkündete Urteil war für den Abt von Ludźmierz günstig. Komes Zdzisław erhielt lediglich als ein Verwandter des Klosterstifters Ehrenschirmherrschaft über die Kirche für sich selbst und seinen Nachkommen.

$22 K D M$, Bd. 1, Nr. XL, S. 44-45.

$23 K D M$, Bd. 1, Nr. XXVI, S. 31-32.

${ }^{24} K D M$, Bd. 1, Nr. XL, S. 44-45; E. Łużyniecka, J. M. Marszalska, Szczyrzyc..., S. 93.
} 
Schamhafte den Verkauf des von Ścibor und Strachota, den Söhnen eines gewissen Nikolaus, erworbenen Dorfes Ściborzyce an das Kloster in Szczyrzyc zum Preis von 30 Griwienka²5.

Die Stiftung von Ludźmierz-Szczyrzyc war die dreizehnte Zisterzienserstiftung in Polen. Zuvor waren Zisterzienserklöster in folgenden Ortschaften entstanden: in Kleinpolen in Jędrzejów (II40/II49), Sulejów (II76/II77), Wąchock (II79), Koprzywnica (II85) und KaciceMogiła (I2I8-I222), in Großpolen in Łekno-Wągrowiec (II42/II53?), Ląd (II75?), ParadyżGościkowo (I230/I235) und Obra (I23I/I238), in Westpommern in Kołbacz (Kolbatz) (II73), in Pommerellen in Oliwa (Oliva) (II86) sowie in Schlesien in Henryków (Heinrichau) (I227) ${ }^{26}$.

Die ursprünglichen Überschreibungen an das Kloster in Szczyrzyc betrafen Güter in der Umgebung von Ludźmierz, Szczyrzyc und Mogilany. Ein Bestandteil der Güter von Szczyrzyc war das Dorf Godusza und ein Teil des Dorfes Gruszów, die Teodor $1235^{27}$ von Zdzisław gekauft hatte; zu den Gütern von Mogilany gehörten Krzyszkowice, das teilweise von Teodor erworben und teilweise vom Mutterkloster in Jędrzejów abgezahlt wurde ${ }^{28}$, Bolechowice sowie die Dörfer Latoszyn und Straszęcin, die I239 gegen Droginia getauscht wurden ${ }^{29}$.

Auch nach der Verlegung des Klosters von Ludźmierz nach Szczyrzyc war weiterhin Tecelin der Abt (er starb I255). In dieser Funktion wird er in einer Urkunde von I252 erwähnt, die sich auf den Ankauf des Dorfes Kurdwanów von den Prämonstratensern von Brzesko und den Prämonstratenserinnen von Zwierzyniec bezieht ${ }^{30}$. Quellenkundlich ist er bis I255 belegt: Er taucht in der schon erwähnten Urkunde vom IO. Mai I254 auf ${ }^{\text {II }}$, in der Klemens und Marek, die Neffen des Wojewoden Teodor, das Eigentumsrecht des Kloster über die nah gelegenen Ortschaften bestätigen. Zum letzten Male ist er in einer Urkunde von I255 erwähnt, in der Herzog Bolesław V. der Schamhafte gemeinsam mit seiner Mutter Grzymisława und seiner Ehefrau Kunigunde dem Kloster einige Privilegien verleiht, dem Abt Tecelin sowie seinen Amtsnachfolgern und dem ganzen Konvent von Szczyrzyc gegenüber verbindlich

25 [...] Boleslaus dictus Pudicus dux Cracoviae et Sandomiriae testatur, Stiborium et Strachotam filios condam Nicolai, villam Ściborzyce coenobio Cisterciensum Ciriciensi LXXXIII marcis vendidisse [...]. Vgl. KDM, Bd. 1, Nr. XXXVIII, S. 43; E. Łużyniecka, J. M. Marszalska, Szczyrzyc..., S. 23, 90.

26 MCP, Bd. 2, hrsg. A.M. Wyrwa, J. Strzelczyk, K. Kaczmarek, Poznań 1999, S. 14. A.M. Wyrwa, Cystersi. Geneza, duchowość, organizacja życia w zakonie (do XV wieku) i poczatki fundacji na ziemiach polskich. In: Cystersi w Polsce, hrsg. D. Olszewski, Kielce 1990, Tabelle Nr. 3, S. 35.

27 KDM, Bd. 1, Nr. XVIII, S. 24; E. Łużyniecka, J. M. Marszalska, Szczyrzyc, S. 84; B. Kwiatkowska-Kopka, Ludźmierz-Szczyrzyc. In: MCP, Bd. 2, S. 220.

28 KDM, Bd. 1, Nr. XXII, S. 27-28; E. Łużyniecka, J. M. Marszalska, Szczyrzyc..., S. 86. B. Kwiatkowska-Kopka, Ludźmierz-Szczyrzyc. In: MCP, Bd. 2, S. 221.

29 KDM, Bd. 2, hrsg. F. Piekosiński, Kraków 1886, Nr. CCCCXVI, S. 61-62; B. Kwiatkowska-Kopka, Ludźmierz-Szczyrzyc. In: MCP, Bd. 2, S. 221.

30 ,, [...] Domino Thecelino Abbati et conventui de chyriche ordinis cisterciensis, vendidimus pro triginta tribus marcis puri argenti [...]. Arch. i BOCist. Pergamenturkunde. sygn. 9; B. Reydlewicz, Provisio ad mensam Conventualem Sciriciensem Ordinis Cisterciensis, Cracoviensis Dioecesis pro fratribus Ab Illustrissimo Revrendissimo Duo Joachimo de Mstow Mstowski Abbate Regulari huius Conventus Anno Domini 1642, Die 24 gloris Assignata ac de Determinata [...] Anno 1760 , Sign. 754, S. 228; KDM, Bd. 1, Nr. XXXIX, S. 43-44; E. Łużyniecka, J. M. Marszalska, Szczyrzyc..., S. 91; S. Zakrzewski, Najdawniejsze dzieje klasztoru cystersów w Szczyrzycu (12381382). Przyczynek do dziejów osadnictwa na Podhalu..., S. 37.

31 KDM, Bd. 1, Nr. XL, S. 44-45. 
sein und seiner Nachfolgern Wohlwollen erklärt und dem Kloster das Recht zusichert, von den erwähnten Klostergütern den Zehnten zu erheben ${ }^{32}$.

Die zweitälteste Stiftung im Podhale ist das Kloster der Klarissenschwestern in Sandez. Von Anfang an war die Stiftung mit Kunigunde aus der ungarischen Árpáden-Dynastie (I234-I292) verbunden; sie war die Herzogin von Kleinpolen-Sandomir und KleinpolenKrakau und Ehefrau von Bolesław V. dem Schamhaften (gest. I279) ${ }^{33}$. Ihre Tatkraft und ihr Politikverständnis kamen nach dem Tode von Bolesław V. dem Schamhaften im Dezember I279 vollends zum Vorschein. Der Krakauer Thron wurde vom Bolesławs Neffen, Leszek dem Schwarzen (um I240/I242-I288), übernommen. Kunigunde, die seitdem den Titel domina de Sandecz führte, erschien - wie ihre Vita bezeugt - schon auf der Beerdigung ihres Ehegatten in einer Nonenkutte; danach begab sie sich mit ihrem Hof nach Sandez, wo sie das Klarissenkloster stiftete ${ }^{34}$. Dabei ist zu betonen, dass Kunigunde zu Lebzeiten Bolesławs V. des Schamhaften nicht im Sandezer Land weilte; gleichwohl zeigt die Überlieferung, dass sie auf diesem Gebiet eine Reihe von Verwaltungsakten vollzogen hat. Die am meisten auffallende Maßnahme war die von ihr verordnete Ablösung des Frondienstes durch den Lehnzins, die einen rasch fortschreitenden Besiedlungsprozess sowie die Gründung der Stadt Sandez zur Folge hatte ${ }^{35}$.

Die Gründe für die Stiftung, die in der - in mehr als zehn Kopien erhalten gebliebenen Stiftungsurkunde vom 6. Juli I280 genannt werden, sind fast ausschließlich religiöser Natur $^{36}$ : „Wir, Kunigunde, Witwe des selig entschlafenen Herrn Bolesław, einst Herzogen zu Krakau und Sandomir, Herrscherin und Herzogin zu Sandez, nachdem wir tief in unserem Herzen und mit aufrichtiger Frömmigkeit erwogen hatten, nichts wird im Jüngsten Gericht hilfreicher werden und nichts wird dem Gerechten Richter, der den Gerechten Leben und den Gottlosen Tod zuteilt, besser besänftigen als Werke der Barmherzigkeit, die die Wohltuenden selbst zur Tür der glücklichen Ewigkeit führen, haben bestimmt, für eigene sowie meines verstorbenen Ehegatten Erlösung ein Kloster für die Schwestern von Hl. Klara zu erbauen und auszustatten“"37.

Nach dem Wunsch der Stifterin sollte das Kloster ein wichtiges kulturelles Zentrum am südlichen Rande Kleinpolens sowie ein Zentrum des religiösen Lebens werden, das weit über die Grenzen des Sandezer Land ausstrahlen sollte ${ }^{3}$. Die Wahl von Sandez für den Klostersitz war keineswegs zufällig. Unter den 29 Ortschaften des Sandezer Landes, die der Herzogin Kunigunde gehörten, war Sandez die einzige mit Stadtrechten, die sie vor I273 erhalten hatte. Die Stadt war auch Sitz der Kastellanei, die schon in den Quellen von I224 erwähnt wurde sowie Sitz des Dekanats der Krakauer Diözese, das in der ersten Hälfte des I3.

32 [...] Ideo dominum Tislinum abbatem de Cyricz et omnes eius succesores et ipsius Ecclesiam in honore beate Mariae virginis constructam, in nostram et nostrorum successorum perhenniter protectionem recipimus specialem [...], KDM, Bd. 1, Nr. XLII, S. 47-48; B. Biros, Dzieje opactwa ... (Ms.), S. 10; S. Zakrzewski, Najdawniejsze dzieje klasztoru cystersów w Szczyrzycu (1238-1382)..., S. 15.

33 M. Michalski, Kobiety i świętość w żywotach trzynastowiecznych księżnych polskich, Poznań 2004, S. 69 -70.

34 Ebd., S. 71.

35 Ebd.

36 B. Kumor, Fundacja starosądeckiego klasztoru i parafie na Sądecczyźnie fundowane przez PP. Klaryski. In „Tarnowskie Studia Teologiczne”, 10/1986, S. 157.

$37 K D M$, Bd. 2, hrsg. F. Piekosiński, Kraków 1886, Nr. 487, S. 145.

38 K. Szwarga, Społeczny charakter pielgrzymek starosądeckich XIV-XVII w., „Rocznik Teologiczno-Kanoniczny", 14/1967, H. 4, S. 27-37. 
Jahrhunderts entstanden war. Sandez, später Alt-Sandez genannt, lag an einem Handelsweg von Krakau nach Ungarn und war damals eine große, bevölkerungsreiche und lebendige Stadt im Grenzgebiet ${ }^{39}$. In der Stiftungsurkunde verpflichtete sich Kunigunde aus dem ÁrpádenGeschlecht, Ehegattin von Bolesław, dem Herzog zu Krakau, Sandomir etc., ein coenobium seu claustrum für den Klarissenorden zu errichten, um den heiligen Glauben zu verbreiten und Erlösung für sie und ihren Ehemann zu erlangen. Das neu gegründete Kloster sollte zu einer Abtei erhoben werden, und die Hauptaufgabe der dort ansässigen Nonnen waren der „Dienst Gottes tags und nachts“, das „Wandeln in Gottesfurcht und Heiligkeit“ sowie die „Gerechtigkeit vor dem Herrn“. Sie sollten, „indem sie sich verleugnen, eher einen engen Weg und ein schmales Tor wählen, die zum ewigen Leben führen“. Ein so gesetztes Ziel deckte sich mit dem Ideal der franziskanischen Frömmigkeit und Spiritualität. Wichtige Bestimmungen enthält der zweite Teil der Urkunde. Die heilige Stifterin Kunigunde - vom Verlangen erfüllt, dass ,dem Kloster an irdischer Hilfe nicht fehlt und so sich die Nonnen umso mehr dem geistigen Leben widmen können,,- verschreibt darin dem von ihr gestifteten Kloster die Stadt [Alt-]Sandez und 28 Dörfer [...] ,,samt Flüssen, Mühlen, Teichen, Fischereiwesen, Hochwäldern, Wäldern, Jagdwesen, Beuten sowie allen Nutzländern und Ländereien, die diesen Dörfern seit Langem gehören“ [...]. Aus der Urkunde geht übrigens hervor, dass die gestiftete Abtei auch erhebliche Einkünfte vom Sandezer Zoll erhielt ${ }^{40}$.

Die Stiftung entstand schon in demselben Jahre, in dem die Urkunde ausgestellt wurde. Dazu trug das gegenüber der Stiftung schwankende Verhalten des Krakauer Herzogs Leszek des Schwarzen bei, der zwar zunächst seine Zustimmung erteilte, doch noch in demselben Jahre Bemühungen aufnahm, die Stiftung aufzuheben und das Vermächtnis der Herzogin Kunigunde zu widerrufen. Die Sache gelangte vor das Tribunal des Heiligen Stuhls; danach stellte Leszek der Schwarze - dank der Vermittlung des päpstlichen Gesandten Filip - am 3I. Oktober I280 in Czchów eine Urkunde aus, in der er sich verpflichtet, die Güter von Kunigunde nicht zu behelligen und andere davon abzuhalten, ihnen Schaden zufügen. Letztlich wurde durch Vermittlung des Krakauer Bischofs Paweł von Przemankowo (gest. I292) am 2. Januar I28I ein Vergleich zwischen dem Herzog und der Stifterin geschlossen ${ }^{4}$.

Hier ist hervorzuheben, dass die Stiftung zu ihrer Zeit die reichste franziskanische Stiftung in Polen und zugleich dort erst das zweite Klarissenkloster überhaupt war. Bis I280 gab es in Polen nur ein einziges Klarissenkloster, das von der seligen Salomea unter Mitwirkung ihres Bruders, des Herzogs Bolesław V. des Schamhaften, in Zawichost gestiftet und 1257 nach Skała bei Krakau verlegt worden war. Aus Skała wurden dann die ersten Klarissinnen nach Alt Sandez geschickt. Nach einer Überlieferung von I287 wurde das Alt-Sandezer Kloster von 70 Nonnen bewohnt, während im I5. Jahrhundert ihre Zahl nach Jan Długosz 60 betrug $^{42}$. Hier sei ergänzend erwähnt, dass es in der Umgebung der seligen Salomea und der heiligen Kunigunde und im Milieu der ersten Klarissinnen Bücher gab. Das wird durch das von der seligen Salomea - der ersten polnischen Klarissin - errichtete Testament bestätigt, das im I9. Jahrhundert von Franciszek Piekosiński im Diplomatischen

39 B. Kumor, Fundacja starosądeckiego klasztoru i parafie na Sądecczyźnie..., S. 160.

40 KDM, Bd. 2, hrsg. F. Piekosiński, Nr. 487, S. 146.

41 Ebd, Nr. 490, S. 149-150.

42 B. Kumor, Fundacja starosądeckiego klasztoru i parafie na Sądecczyźnie..., S. 162. 
Kodex Kleinpolens ${ }^{43}$ herausgegeben wurde: Dort spricht sie vom Ankauf der Manuskripte für das Kloster, die nach ihrem Tode den Franziskanerbrüdern zufallen sollen. Im letzten Teil des Testament, das am 28. August I268 im Klarissenkloster in Skała in Anwesenheit des Krakauer Domherrn Tomasz, des Beichtvaters Justyn und einiger Guardiani von verschiedenen Franziskanerklöstern aufgesetzt wurde, findet sich die Formulierung: „Bücher dagegen, sowohl kirchliche als auch jene der Belehrung dienenden (libros chorales quam ad studium pertinentes), sowie diejenigen, die ich für Bruder Borysław ankaufte, überlasse ich nach seinem Dahinscheiden den Brüdern zum Gebrauch, welche bei den erwähnten, meinen herzallerliebsten Schwestern bleiben und ihnen den geistigen Trost erweisen werden. Ich verbiete es also mit aller Strenge, dass jemand wagt, sie von der Wohnung der besagten Brüder wegzunehmen. Damit diese Bestimmung unverletzt bleibt, ist sie mit den Siegeln meines allerliebsten Bruders, des Herzogs zu Krakau und Sandomir, wie auch des ehrwürdigen Vaters Paul, des Krakauer Bischoffs, und dem Meinen bestätigt ${ }^{\star 44}$.

Es besteht kein Zweifel, dass auch die Sandezer Herzogin Kunigunde Gebetbücher zum Eigengebrauch besaß. In ihrer vor I400 von einem franziskanischen Hagiographen niedergeschriebenen Vita steht: ,gewöhnlich beendete sie alle Chorgebete jeweils mit zehn polnischen Psalmen“. In Anlehnung an die Eintragung: et sic totum Psalterium per ordinem complebat, wurde abgeleitet, dass die Herzogin des Sandezer Landes täglich die Psalmen Davids gesprochen hat; es musste im Kloster also eine Übersetzung des Psalters geben, die vermutlich im Sandezer Franziskanerkloster angefertigt worden war ${ }^{45}$. Kunigunde besaß auch die Regel des H1. Franziskus sowie eine Vita des Ordensgründers zum eigenen Gebrauch. Im Kloster waren auch die wichtigsten, zur Liturgiefeier unentbehrlichen liturgischen Codices (Messbücher, Antiphonalien, Gradualien) vorhanden.

Es ist zu betonen, dass sich keines der später gestifteten Franziskanerklöster in Groß- sowie Kleinpolen in Hinsicht auf den Reichtum seiner Güter und Privilegien mit der Klosterstiftung in Sandez messen konnte. Die dem Kloster überschriebenen Dörfer lagen am oberen Lauf von Dunajez und Poprad und umgaben kranzartig die Alt-Sandezer Stadtanlage. Vom ganzen Dorfkomplex waren Ujanowice und Strzeszyce die nördlichsten Ortschaften, am südlichsten gelegen war Podoliniec in der Zips, während Zagorzyn und Czerniec die westlichsten und Siedlec sowie Słowikowa die östlichsten Dörfer bildeten ${ }^{46}$. Die Stiftung der Hl. Kunigunde erhielt am 5. Juli I28Idurch die Bulle des Papstes Martin V Cum a nobis petitur und danach am 8. November 1292 durch König Wenzel II. von Böhmen Rechtskraft47. Von der erheblichen religiös-gesellschaftlichen Bedeutung des Alt-Sandezer Klosters zeugt bereits die Tatsache, dass im Laufe von Ioo Jahren in der Umgebung von Alt-Sandez zehn Pfarreien gegründet wurden. Dieser Gründungsprozess dauerte bis zum Ende des I4. Jahrhunderts. Dabei ist zu erwähnen, dass die Krakauer Herzogin Kunigunde auch die Stifterin von mehreren Kirchen, u. a. in Bochnia und Nowy Korczyn in Kleinpolen war und dass sie darüber hinaus die Brüder von der Buße der Märtyrer sowie den Prämonstratenserinnenorden, den

43 M. Hornowska, H. Zdzitowiecka - Jasieńska, Zbiory rękopiśmienne w Polsce średniowiecznej, Warszawa 1947, S. 60 .

44 Ebd., S. 61.

45 Ebd., S. 61-62.

46 B. Kumor, Fundacja starosądeckiego klasztoru i parafie na Sądecczyźnie..., S. 161.

${ }^{47} K D M$, Bd. 2, hrsg. F. Piekosiński, Nr. 521, S. 187-188. 
sie in Krzyżanowice an der Nida ansiedelte und für den sie eine Klosterkirche stiftete, nach Polen holte ${ }^{48}$. Bald nach dem - am 24. Juli I292 erfolgten - Tode von Kunigunde und ihrer Beisetzung im Alt-Sandezer Kloster begann sich ihr Kultus zu verbreiten. Die ersten von ihr gewirkten Wunder wurden I307, vermutlich auf Veranlassung von Hedwig von Kalisch niedergeschrieben - der Ehefrau von Władysław I. Ellenlang und der nächsten, nach Gryfina, der Ehefrau von Leszek dem Schwarzen, Herzogin des Sandezer Landes ${ }^{49}$. Nach 1320 wurde ihre erste Vita verfasst, die danach eine Umarbeitung erfuhr. Der Kultus der Krakauer Herzogin Kunigunde - der Stifterin des Alt-Sandezer Klosters - verbreitete sich rasch in ganz Kleinpolen, ihre umfangreiche Vita wurde im I5. Jahrhundert von Jan Długosz (I47I-I473) niedergeschrieben und Anfang des I7. Jahrhunderts ins Polnische übersetzt ${ }^{50}$.

Beide hier besprochenen Stiftungen im Podhale, sowohl das Zisterzienserkloster in Szczyrzyc als auch die Franziskanerstiftung in Alt-Sandez, trugen wesentlich zur religiösen, kulturellen und gesellschaftlichen Entwicklung dieser Gegend bei, denn ihre Stifter einerseits der Krakauer Wojewode Teodor Gryfita, andererseits die Krakauer Herzogin Kunigunde aus dem Árpáden-Geschlecht, die später heiliggesprochen wurde - waren höchst einflussreiche Personen, die mit ihren Werken nicht nur den Besiedlungsprozess im Podhale und die wirtschaftliche Entwicklung in Polen, sondern vielmehr auch das religiöse und kulturelle Leben im Piasten-Staat insgesamt zu fördern vermochten.

\section{Cracow voivode Teodor Gryfita (died after 1237) and Saint Kinga (1234-1292) from the Arpad dynasty, founders of the oldest monasteries in Podhale Summary}

Both of the above mentioned $13^{\text {th }}$ century monastery foundations in Podhale -the Cistercian Szczyrzyc as well as the Franciscan Stary Sącz - played important religious, cultural and social role in the development of this region. Their founders were important people, both the voivode of Cracow Teodor Gryfita and the Cracow duchess Kinga of the Arpad family (later a saint) inscribed themselves for the work of monastery foundations in Podhale in the colonization and economic process but above all the religious and cultural life in the then Piast state.

Keywords: monastery, Teodor Gryfita, Cistercian, Saint Kinga, Order of Saint Clare

\section{Wojewoda krakowski Teodor Gryfita (zmarly po 1237) i św. Kinga (1234-1292) z dynastii Arpadów, założyciele najstarszego klasztoru na Podhalu Streszczenie}

Obie z wymienionych XIII-wiecznych fundacji klasztornych na Podhalu, zarówno cysterski Szczyrzyc jak i franciszkański Stary Sącz, odegrały ważną religijną, kulturową i społeczną rolę w rozwoju tego regionu. Ich fundatorzy, to osoby znaczące, zarówno wojewoda krakowski Teodor Gryfita jak i księżna krakowska Kinga z rodu Arpadów (późniejsza święta),

\footnotetext{
48 M. Michalski, Kobiety i świętość w żywotach trzynastowiecznych księżnych polskich, Poznań 2004, S. 71-72.

49 Ebd.

50 Jan Długosz, Vitae beatae Kunegundis, hrsg. A. Przeździecki. In: derselbe, Opera omnia, Bd. 1, Kraków 1887, S. 183-336.
} 
wpisywali się podjętym dziełem fundacji klasztornych na Podhalu w proces kolonizacyjny, gospodarczy, ale nade wszystko religijny i kulturowy w ówczesnym państwie piastowskim.

Słowa kluczowe: Klasztor, Teodor Gryfita, Cystersi, św. Kinga, Klaryski

\section{BIBLIOGRAFIA}

Biros B., Dzieje opactwa oo. Cystersów w Szczyrzycu na tle życia i zastug opatów tegoż klasztoru, Szczyrzyc 1950.

Długosz J., Liber Beneficiorum Dioecesis Cracoviensis, Bd. 3, Cracoviae I864, S. 436.

Dobosz J., Wietesko L., Jędrzejów. In: Monasticon Cisterciense Poloniae Bd. 2, hrsg. A.M. Wyrwa, J. Strzelczyk, K. Kaczmarek, Poznań 1999.

Hornowska M., Zdzitowiecka - Jasieńska H., Zbiory rękopiśmienne w Polsce średniowiecznej, Warszawa 1947.

Jan Długosz, Vitae beatae Kunegundis, hrsg. A. Przeździecki. In: derselbe, Opera omnia, Bd. I, Kraków I887, S. I83-336.

Kolor W., Cysterski klasztor w Szczyrzycu, I88I, S. I, (Typoskript), ohne Signatur.

Kumor B., Fundacja starosadeckiego klasztoru i parafie na Sadecczyźnie fundowane przez PP. Klaryski, „Tarnowskie Studia Teologiczne”, Io/1986, S. 157.

Kwiatkowska-Kopka B., Ludźmierz-Szczyrzyc In: Monasticon Cisterciense Poloniae, Bd. 2, hrsg. A.M. Wyrwa, J. Strzelczyk, K. Kaczmarek, Poznań I999.

Leszczyńska-Skrętowa Z., Sikora F., T. I, H. I, Wrocław-Warszawa-Kraków-Gdańsk 1980.

Łużyniecka E., Marszalska J. M., Szczyrzyc, Dzieje budowy opactwa cysterskiego, Wrocław 2005.

Marszalska J.M., Opactwo cystersów w Szczyrzycu od XIII do końca XX wieku, Kraków 201 I.

Marszalska M., Opactwo cystersów w Szczyrzycu od XIII do końca XX wieku. Dzieje, gospodarka, kultura, Kraków $201 \mathrm{II}$.

Michalski M., Kobiety i świętość w żywotach trzynastowiecznych księżnych polskich, Poznań 2004.

Rafacz J., Dzieje i ustrój Podhala nowotarskiego za czasów dawnej Rzeczypospolitej Polskiej, Warszawa 1935.

Rechowicz M., Początki i rozwój kultury scholastycznej (do końca XIV w.), In: Dzieje teologii katolickiej w Polsce, Bd. I, Średniowiecze, hrsg. M. Rechowicz, Lublin 1974.

Rutkowska-Płachcińska A., Sądeczyzna w XIII i XIV w. Przemiany gospodarcze i społeczne, Wrocław - Warszawa - Kraków I96I.

Sczaniecki P., Gryfici z linii brzeźnickiej i benedyktyni, „Studia Historyczne“, 30/1987, H. I, S. 5; $15-16$.

Stownik historyczno-geograficzny województwa krakowskiego w Średniowieczu, hrsg. F. Sikora, T. 3, H. 3. Kraków 2000, S. 74.

Szwarga K., Społeczny charakter pielgrzymek starosadeckich XIV-XVII w, „Rocznik Teologiczno-Kanoniczny", I4/1967, H. 4, S. 27-37.

Wyrwa A.M., Cystersi. Geneza, duchowość, organizacja życia w zakonie (do XV wieku) i poczatki fundacji na ziemiach polskich, In: Cystersi w Polsce, hrsg. D. Olszewski, Kielce 1990.

Zakrzewski S., Najdawniejsze dzieje klasztoru cystersów w Szczyrzycu (I238-I382). Przyczynek do dziejów osadnictwa na Podhalu, Kraków I9oI.

Zawadzka J., Proces fundowania opactw cysterskich w XII i XIII wieku, „Roczniki Humanistyczne", 7/1960, H. 2, S.I2I-I50. 